\begin{tabular}{|c|c|}
\hline 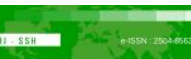 & Malaysian Journal of Social Sciences and Humanities (MJSSH) \\
\hline $\begin{array}{l}\text { Malaysian Journal of } \\
\text { soccial sciences and }\end{array}$ & Volume 6, Issue 1, January 2021 \\
\hline (MJ-sSH) & e-ISSN : 2504-8562 \\
\hline & $\begin{array}{l}\text { Journal home page: } \\
\text { www.msocialsciences.com }\end{array}$ \\
\hline
\end{tabular}

\title{
Pengaruh Pembangunan Penerapan Nilai dalam Pendidikan Abad Ke 21 Terhadap Pembentukan Sahsiah Murid Sekolah Kurang Murid (SKM) Luar Bandar di Sabah
}

\author{
Dg Norizah Ag Kiflee@Dzulkifli' ${ }^{1}$, Roslee Bin Talip ${ }^{1}$, Tan Choon Keong ${ }^{1}$,Soon Singh A/L Bikar Singh', \\ Lee Bih Ni ${ }^{1}$, Rosy Talin ${ }^{1}$, Mad Noor B. Madjapuni ${ }^{1}$ \\ ${ }^{1}$ Fakulti Psikologi dan Pendidikan, Universiti Malaysia Sabah (UMS)
}

Correspondence: Dg Norizah Ag Kiflee@Dzulkifli (dndz@ums.edu.my)

\begin{abstract}
Abstrak
Kajian ini dijalankan bagi mengkaji pengaruh pembangunan penerapan nilai dalam pendidikan abad ke21 terhadap pembentukan sahsiah murid Sekolah Kurang Murid (SKM) luar bandar di Sabah. Selain itu, kajian ini mengkaji perbezaan skor min pembangunan penerapan nilai dalam pendidikan abad ke-21 dan pembentukan sahsiah murid Sekolah Kurang Murid (SKM) luar bandar di Sabah. Kajian ini menggunakan reka bentuk bukan eksperimen dan kaedah kuantitatif. Seramai 209 orang guru SKM telah dipilih untuk dijadikan sampel dalam kajian ini. Sampel ini ditentukan dengan menggunakan kaedah pensamplean rawak mudah. Instrumen soal selidik pula telah digunakan untuk memperoleh maklumat daripada sampel kajian. Data mentah yang diperoleh daripada sampel kajian dianalisis menggunakan perisian Statistical Package for Social Sciences (SPSS) dengan menggunakan analisis statistik inferensi yang melibatkan analisis Regresi Linear. Hasil analisis menunjukkan terdapat pengaruh signifikan yang positif dan kuat antara pembangunan penerapan nilai dalam pendidikan abad ke-21 terhadap pembentukan sahsiah murid Sekolah Kurang Murid (SKM) luar bandar di Sabah (Beta=0.88, t=27.65). Hasil kajian ini diharap dapat memberikan input bermanfaat kepada pelbagai pihak khususnya Kementerian Pendidikan Malaysia dalam usaha meningkatkan kemampuan sekolah untuk melahirkan murid yang bersahsiah dan mampu memberi sumbangan kepada pembangunan negara.
\end{abstract}

Kata kunci: penerapan nilai, pembentukan sahsiah murid, Sekolah Kurang Murid (SKM)

\section{Influence of the Development of Value in 21st Century Education on the Forming of the Student' Personality in Rural Under-Enrolled School (SKM) in Sabah}

\begin{abstract}
This study was conducted to study the influence of the development of values in 21 st century education on the forming of student' personality in rural Under-Enrolled School (SKM) in Sabah. In addition, this study examines the difference in the mean score of the development of value approach in 21st century education and the forming of student' personality in rural Under-Enrolled School (SKM) in Sabah. This study uses non-experimental design and quantitative methods. A total of 209 SKM teachers were selected to be sampled in this study. This sample was determined using a simple random sampling method. Questionnaire instruments were used to obtain information from the respondents. The primary data obtained from the respondents were analyzed using Statistical Package for Social Sciences (SPSS) software using inferential statistics analysis involving Linear Regression analysis. The results of the analysis show that there is a significant positive and strong influence between the development of value
\end{abstract}


approach in 21st century education on the forming of student' personality in rural Under-Enrolled School $(\mathrm{SKM})$ in Sabah $(\mathrm{Beta}=0.88, \mathrm{t}=27.65)$. The results of this study are expected to provide useful input to various parties, especially the Ministry of Education Malaysia in an effort to improve the school's ability to produce students who are personal and able to contribute to the development of the country.

Keywords: value approach, forming of the student' personality, Under-Enrolled School

\section{Pengenalan}

Di Malaysia, hampir semua negeri termasuk kawasan bandar seperti Kuala Lumpur mempunyai sekolah bertaraf Sekolah Kurang Murid (SKM). Namun begitu, jumlah bilangan SKM adalah paling banyak terdapat di negeri yang mempunyai struktur geografi yang kompleks seperti kawasan berbukit dan sungai, khususnya di Sabah dan Sarawak (Nitce, Azlin \& Jamalul, 2017). Walaupun, bilangan murid di sekolah ini adalah kurang daripada sekolah biasa (Ewington et al., 2008), namun penubuhannya adalah sangat perlu bagi memastikan setiap murid mendapat pendidikan yang sewajarnya. Bukan itu sahaja, penubuhannya yang menjadi medium dalam pembentukan sahsiah pelajar akan memberi kesan terhadap kualiti hidup murid khususnya dalam aspek penampilan diri, sikap, tingkah laku, pemikiran, perasaan, sosial dan rohani. Justeru itu, adalah menjadi tanggungjawab para guru untuk membentuk sahsiah murid dengan menerapkan nilai-nilai murni di dalam dirinya. Sebenarnya tanggungjawab telah lama digalas oleh para guru iaitu membentuk murid yang berketerampilan dan mampu menyumbang kepada pembangunan dan kesejahteraan keluarga, masyarakat dan negara (Nor Aishah \& Mohd. Zolkifli, 2014).

\section{Pernyataan Masalah}

Pembentukan sahsiah diri murid amat dipengaruhi oleh faktor internal dan eksternal murid. Faktor internal merangkumi niat, motivasi dan konsentrasi murid. Manakala, faktor eksternal pula merangkumi sikap dan hubungan luaran murid (Purwokerto, 2007). Murid yang memiliki masalah internal memiliki sahsiah yang kurang baik dan cenderung untuk melakukan perkara-perkara negatif di sekolah seperti melawan guru, membuli, ponteng kelas dan vandalisme (Abdul Rahim et al., 2017; Ab. Halim et al., 2007; Amaludin \& Khadijah, 2007). Sebagai contohnya, murid yang sering tidak hadir ke sekolah menyebabkan guru sukan untuk memerhati dan membentuk dirinya kerana kekangan masa yang dihadapi oleh guru.

Dalam era globalisasi pada hari ini, perkembangan teknologi bukan hanya berlaku di bandar-bandar besar, bahkan turut berkembang di kawasan luar bandar. Oleh itu, pembentukan sahsiah amat penting untuk diterapkan dalam diri murid. Justeru itu, hal ini menjadi semakin penting khususnya pada waktu ini yang mana arus materialistik dan konsumerisme global terus mengikis sahsiah murid dengan menghilangkan nilai-nilai murni daripada kehidupan manusia termasuklah murid-murid, tidak hanya yang tinggal di kota besar, bahkan turut mempengaruhi kawasan pedalaman (Purwokerto, 2007).

Abdul Rahim dan Azharul (2010) menjelaskan bilangan murid yang ramai dan datang daripada pelbagai etnik menyukarkan para guru untuk menerapkan nilai-nilai murni dalam pembelajaran. Hal ini demikian kerana, setiap murid berpegang kepada pegangan etnik dan agama masing-masing. Murid- murid ini berasal berasal daripada pelbagai keturunan, adat resam, sosio-ekonomi, peringkat umur, dan masalah disiplin (Tajulashikin, Fazura \& Mohd Burhan, 2013). Selain itu, pendidikan masa ini lebih berfokus kepada pencapaian akademik murid berbanding pembentukan sahsiah diri mereka dalam pelbagai aspek (Purwokerto, 2007).

Penerapan nilai dalam pendidikan abad ke-21 juga sukar untuk dilaksanakan kerana budaya sekolah itu sendiri yang kurang menyokong kepada penerapan nilai. Sekolah kurang murid tidak memiliki cukup konsep dan instrumen tentang penerapan nilai yang benar-benar dapat diaplikasikan untuk para murid. Hal ini dipersulitkan lagi apabila pihak pentadbiran sekolah yang lebih bersifat administratif dan hanya 
mementingkan perkembangan kurikulum pelajar yakni guru hanya menyampaikan isi pelajaran, membuat penilaian dan memastikan pelajar lulus agar dapat melanjutkan pelajaran ke peringkat yang lebih tinggi dan lebih terarah kepada mengejar sasaran kurikulum dan bukannya pembentukan sahsiah (Purwokerto, 2007).

Rohayati (2004) dan Hashim et al. (2008) menjelaskan ibu bapa yang tidak memainkan peranan dalam membentuk sahsiah diri murid menyebabkan para guru sukar untuk membentuk sahsiah murid di sekolah. Kegagalan ibu bapa dalam membentuk sahsiah anak-anak mereka ini akan menjejaskan masa hadapan mereka. Ibu bapa seharusnya memainkan peranan utama dalam membentuk sahsiah murid iaitu anak-anak mereka dan tidak seharusnya meletakkan keseluruhan tanggungjawab ke atas bahu para guru. Dalam pembentukan sahsiah anak-anak, perkara paling utama yang perlu dilakukan oleh ibu bapa adalah memberikan didikan agama kepada anak-anak mereka (Maznah \& Zakiah, 2010; Ahmad Munawar, Zakaria \& Siti, 2012).

\section{Objektif Kajian}

Kajian ini dijalankan untuk mengkaji pengaruh pembangunan penerapan nilai pendidikan abad ke-21 terhadap pembentukan sahsiah murid Sekolah Kurang Murid (SKM) luar bandar di Sabah.

\section{Hipotesis kajian}

Berikut merupakan hipotesis nol dalam kajian ini:

$\mathrm{Ho}^{1}$ : Tidak terdapat Pengaruh yang signifikan pembangunan penerapan pendidikan abad ke-21 terhadap pembentukan sahsiah murid Sekolah Kurang Murid (SKM) luar bandar di Sabah.

\section{Sorotan Literatur}

\section{Pengaruh pembangunan penerapan nilai dalam pendidikan abad ke-21 terhadap pembentukan sahsiah murid}

Mohamad Khairi dan Asmawati (2010) yang menjelaskan tenaga pengajar atau guru perlulah menekankan penerapan nilai-nilai murni dalam proses pengajaran dan pembelajaran kerana nilai-nilai murni merupakan salah satu asas penting terhadap pembangunan kepada pembentukan nilai murid yang bermoral dan beretika atau dalam erti kata yang lain murid yang memiliki sahsiah yang baik. Oleh hal yang demikian, bagi memastikan penerapan nilai dalam pendidikan benar-benar dapat membantu membentuk sahsiah diri murid maka proses pengajaran perlu dirancang terlebih dahulu oleh guru secara sistematik agar para guru dapat memastikan mereka menggunakan kaedah dan teknik yang bersesuaian mengikut kepada suasana dan situasi yang sesuai bagi mencipta proses pembelajaran yang menekankan penerapan nilai dalam pembentukan sahsiah murid (Norazri, 2015).

Pengkaji-pengkaji luar negara turut menjalankan kajian berkaitan dengan kajian ini. Purwokerto (2007) dalam kajiannya berkaitan dengan pendidikan nilai menjelaskan pendidikan nilai merupakan salah satu bahagian penting dalam pendidikan pada masa ini kerana peranannya sebagai salah satu elemen untuk mengembangkan watak optimisme dalam diri murid atau dalam erti kata yang lain nilai merupakan elemen dalam pembentukan sahsiah diri murid. Thompson (2002) pula, menjelaskan pengajaran sekolah termasuklah penerapan nilai-nilai dalam pembelajaran telah memberi pengaruh yang besar terhadap pembentukan dan perubahan sahsiah murid ke arah yang lebih baik. Hasil kajian beliau menjelaskan para pelajar menyatakan pengajaran guru merupakan pengaruh yang paling besar dalam pembentukan sahsiah diri mereka di samping faktor ibu bapa/keluarga dan rakan sekolah. 
Higgins (2007) serta Talts dan Kukk (2013) menjelaskan penerapan nilai dalam pendidikan menumpukan kepada perkembangan kendiri dan moral murid yang mempengaruhi perkembangan kemahiran sosial murid dan seterusnya pembentukan sahsiah murid. Shoba dan Dan (2015) pula menjelaskan institusi pendidikan bukan sahaja berperanan untuk melengkapkan murid dengan ilmu pengetahuan tetapi juga memainkan peranan untuk membentuk sahsiah murid dengan penerapan nilainilai murni. Oleh itu, pengkaji menegaskan perkembangan murid perlulah sentiasa dipantau dan dibimbing oleh guru agar nilai-nilai murni menjadi sebahagian daripada sahsiah mereka

\section{Metod Kajian}

\section{Reka bentuk, Kaedah dan Teknik Kajian}

Kajian ini menggunakan reka bentuk kajian bukan eksperimen. Kaedah kajian yang dipilih pula ialah kaedah kuantitatif dengan melaksanakan tinjauan bertepatan dengan pendapat Creswell (2009) yang menjelaskan kaedah tinjauan sesuai digunakan bagi kajian yang menggunakan reka bentuk kajian bukan eksperimen. Teknik yang digunakan ialah teknik soalan berasaskan instrumen soal selidik berbentuk tertutup atau berstruktur dan menggunakan skala likert 5-point. Instrumen soal selidik yang digunakan dalam kajian ini terdiri daripada tiga bahagian iaitu Bahagian A (Demografi Responden), Bahagian B (Penerapan Nilai dalam Pendidikan abad ke 21), dan Bahagian C (Pembentukan Sahsiah Murid). Data mentah daripada sampel kajian dianalisis menggunakan perisian Statistical Package for Social Sciences (SPSS) dengan menjalankan ujian statistik inferensi Regresi Linear.

\section{Lokasi Kajian}

Kajian ini hanya dijalankan di daerah Ranau, Sabah disebabkan oleh beberapa kekangan. Antaranya, kekangan masa yang agak singkat untuk menjalankan kajian, penularan wabak Covid-19 yang menyukarkan kajian secara menyeluruh di seluruh Sabah, khususnya di daerah yang berisiko tinggi dan kebanyakkan Sekolah Kurang Murid terletak di daerah Ranau iaitu sebanyak 35 buah sekolah.

\section{Populasi dan Sampel Kajian}

Populasi kajian adalah seramai 459 orang guru Sekolah Kurang Murid di daerah Ranau. Namun begitu, daripada jumlah ini, hanya 209 orang guru sahaja yang dipilih untuk menjadi sampel kajian. Kaedah pensampelan yang digunakan dalam kajian ini adalah kaedah pensampelan rawak mudah. Hal ini bermaksud setiap guru daripada populasi mempunyai peluang yang sama rata untuk dipilih sebagai sampel kajian bertepatan dengan pendapat Merican (2009), menerusi pensampelan rawak mudah, setiap elemen dalam populasi mempunyai peluang yang sama untuk dipilih sebagai responden. Dalam menentukan saiz sampel pula, jadual penentuan saiz sampel mengikut Krejcie dan Morgan (1970) telah dirujuk. Berdasarkan jadual penentuan saiz sampel Krejcie dan Morgan (1970), telah ditetapkan berapakah jumlah sampel yang perlu diambil daripada jumlah populasi yang ada. Seterusnya, bagi menambahkan lagi kebolehpercayaan bilangan sampel yang dipilih adalah mencukupi, pengiraan jumlah bilangan sampel yang diperlukan mengikut formula pengiraan saiz sampel Cochran (1977) juga telah dilaksanakan (Bartlett, Kotrlik \& Higgins, 2001).

\section{Kesahan dan Kebolehpercayaan Instrumen Kajian}

Sebelum instrumen diedarkan kepada sampel kajian dalam kajian sebenar, analisis kesahan dan kebolehpercayaan item telah dilaksanakan semasa fasa kajian rintis. Dalam kajian rintis sebanyak 100 orang guru Sekolah Kurang murid telah dijadikan sampel bertepatan dengan pendapat Connely (2008) yang menyarankan jumlah sampel bagi kajian rintis adalah sebanyak 10 peratus daripada jumlah populasi kajian. Oleh itu, sampel yang terlibat melebihi jumlah sampel kajian rintis yang diperlukan dalam kajian ini. Bagi menguji Kesahan Instrumen soal selidik, ujian EFA menggunakan perisian SPSS telah dijalankan. Jadual 1 menunjukkan hasil analisis terhadap Indeks Kaiser-Meyer-Oklin (KMO) dan ujian 
Bartlett's bagi ujian kecukupan sampel dan item soal selidik serta ujian kebolehpercayaan dengan melihat nilai Alpha Cronbach.

Jadual 1: Analisis Kesahan dan Kebolehpercayaan Instrumen Kajian Rintis

\begin{tabular}{llllll}
\hline Konstruk yang diuji & $\begin{array}{l}\text { Bilangan } \\
\text { item }\end{array}$ & $\begin{array}{l}\text { Bilangan } \\
\text { guru }\end{array}$ & KMO & $\begin{array}{l}\text { Bartlett's } \\
\text { (Sig) }\end{array}$ & $\begin{array}{l}\text { Alpha } \\
\text { Cronbach }\end{array}$ \\
\hline $\begin{array}{l}\text { Pembangunan Penerapan } \\
\text { Nilai dalam Pendidikan } \\
\text { Abad ke-21 }\end{array}$ & 20 & 100 & 0.81 & 0.00 & 0.91 \\
$\begin{array}{l}\text { bentukan Sahsiah Murid } \\
\text { (10 }\end{array}$ & 10 & 100 & 0.72 & 0.00 & 0.82 \\
\hline
\end{tabular}

Berdasarkan jadual 1, nilai KMO bagi konstruk pembangunan penerapan nilai dalam pendidikan abad ke 21 adalah 0.81 dan nilai KMO bagi pembentukan sahsiah murid adlah 0.72. Nilai kedua-dua konstruk yang diuji melebihi nilai minimum bagi ujian KMO iaitu 0.50. Bagi ujian Bartlett's pula, kesemua konstruk yang diuji berada pada aras signifikan 0.00. Hair, Black, Babin, dan Anderson (2010) menjelaskan item layak untuk dianalisis faktor dan diterima sekiranya nilai KMO melebihi 0.50 dan mempunyai nilai yang signifikan. Oleh itu, kedua-dua konstruk yang diuji dalam kajian ini sesuai untuk dianalisis faktor. Selain melihat pada nilai KMO dan Bartlett's, kesahan item diperincikan dengan membuat ujian kesahan konstruk dengan melihat kepada nilai faktor muatan (factor loading). Nilai Alpha Cronbach juga menunjukkan kedua-dua instrumental mempunyai tahap kebolehpercayaan yang tinggi iaitu penerapan nilai dalam pendidikan abad ke-21 (0.91) dan pembentukan sahsiah murid $(0.82)$.

\section{Hasil Kajian}

\section{Ho1: Tidak Terdapat Pengaruh Yang Signifikan Pembangunan Penerapan Nilai Pendidikan Abad ke-21 Terhadap Pembentukan Sahsiah Murid Sekolah Kurang Murid (SKM) Luar Bandar di Sabah}

Jadual 2 menunjukkan ringkasan ujian Regresi Mudah. Manakala, jadual 3 pula, menunjukkan hasil ujian Anova. Hasil ujian regresi yang dijalankan menunjukkan adanya regresi yang kuat model regresi yang mengandungi variabel tetap iaitu pembangunan penerapan nilai pendidikan abad ke-21 boleh menerangkan secara signifikan sebanyak 88 peratus daripada varians dalam variabel bersandar iaitu pembentukan sahsiah murid $[\mathrm{F}(1,207)=764.61, \mathrm{P}<0.05)]$. Jadual 1.3 pula, menunjukkan hasil analisis koefisien yang menunjukkan pekali regresi penerapan nilai dalam pendidikan abad ke-21 (Beta $=0.88$, $\mathrm{t}=27.65),(\mathrm{P}<0.05)$ merupakan peramal signifikan terhadap pembentukan sahsiah murid.

Oleh itu, dapat disimpulkan, pembangunan penerapan nilai pendidikan Abad ke-21 mempengaruhi pembentukan sahsiah diri murid Sekolah Kurang Murid di Sabah. Justeru itu, hipotesis nol yang menyatakan terdapat pengaruh yang signifikan pembangunan penerapan nilai pendidikan abad ke-21 terhadap pembentukan sahsiah murid Sekolah Kurang Murid (SKM) luar bandar di Sabah ditolak.

Jadual 2: Ringkasan Model

\begin{tabular}{ccccc}
\hline Model & $\mathbf{R}$ & R Square & $\begin{array}{c}\text { Adjusted } R \\
\text { Square }\end{array}$ & $\begin{array}{c}\text { Std. Error of the } \\
\text { Estimate }\end{array}$ \\
\hline 1 & $.88^{\mathrm{a}}$ & .78 & .78 & .21 \\
\hline
\end{tabular}

a. Peramal: (Tetap), Penerapan Nilai

b. Variabel Bersandar: Pembangunan Sahsiah Murid 
Jadual 3: Analisis ANOVA

\begin{tabular}{ccccccc}
\hline & Model & Sum of Squares & df & Mean Square & F & Sig. \\
\hline 1 & Regression & 35.16 & 1 & 35.16 & 764.61 & $.00^{\mathrm{b}}$ \\
& Residual & 9.52 & 207 & 0.04 & & \\
Jumlah & 44.68 & 208 & & & \\
\hline
\end{tabular}

a. Variabel Bersandar: Pembangunan Sahsiah Murid

b. Peramal: (Tetap), Penerapan Nilai

Jadual 4: Analisis Koefisien

\begin{tabular}{ccccccc}
\hline \multirow{2}{*}{ Model } & \multicolumn{2}{c}{$\begin{array}{c}\text { Unstandardized } \\
\text { Coefficients }\end{array}$} & $\begin{array}{c}\text { Standardized } \\
\text { Coeffiients }\end{array}$ & t & Sig. \\
\cline { 3 - 5 } & $\mathbf{B}$ & Std Error & Beta & & \\
\hline 1 & (Tetap) & 1.50 & .107 & & 14.08 & .00 \\
& Penerapan Nilai & 0.77 & .028 & .88 & 27.65 & .00 \\
\hline
\end{tabular}

a. Variabel Bersandar: Pembangunan Sa hsiah Murid

\section{Perbincangan Kajian}

Dapatan kajian ini selari dengan dapatan Asmawati et al. (2015) yang menjelaskan penerapan nilai murni dalam diri murid yang diterapkan menerusi pelbagai cara oleh para guru mampu melahirkan murid yang seimbang dari segi jasmani, emosi, rohani, intelek, dan sahsiah. Nor Suhara dan Jamil (2010) pula menjelaskan penerapan nilai murni seperti perasaan muhibah, perpaduan, dan integrasi amat penting dalam mempengaruhi sahsiah diri murid. Dapatan kajian ini juga selari dengan pendapat Mohamad Khairi dan Asmawati (2010) yang menjelaskan tenaga pengajar atau guru perlulah menekankan penerapan nilai-nilai murni dalam proses pengajaran dan pembelajaran kerana nilai-nilai murni merupakan salah satu asas penting yang mempengaruhi pembentukan sahsiah murid.

Dapatan kajian ini disokong oleh kajian Abd. Rahim (2001) yang menjelaskan penghayatan, pengetahuan, dan kefahaman terhadap nilai-nilai murni mempunyai kesan atau pengaruh positif dengan pembentukan sahsiah diri murid yakni nilai murni yang diterapkan dalam diri murid menimbulkan kesedaran dan penghayatan kepada murid tentang pelbagai isu moral yang seterusnya menguasai dan mempengaruhi sahsiah murid tersebut. Selain itu, Mohd Khairi dan Asmawati (2010) juga menjelaskan penghayatan nilai murni dalam kalangan murid amat penting, kerana nilai murni yang dihayati itu akan mempengaruhi bentuk sahsiah diri murid tersebut. Nilai-nilai tersebut juga dapat membentuk sikap dan pemikiran murid yang mana penghayatan nilai-nilai murni ini akan membolehkan murid untuk membuat keputusan yang wajar dan bertanggungjawab ke atas sahsiah dirinya (Mohd Arif et al., 2005).

Selain itu, kajian oleh Najuah (2017) turut menjelaskan pembentukan sahsiah murid muncul apabila murid mengamalkan nilai-nilai murni seperti amanah, jujur, menepati masa, empati, bersemangat, ikhlas, dan koperatif. Hal ini seterusnya akan membuat murid cenderung untuk meninggalkan amalan negatif seperti pemarah, tidak menepati masa, biadab, dan mungkir janji (Sjarkawi, 2008; Najuah, 2017). Hal ini turut disokong oleh Khasnor dan Sanitah (2014) yang menjelaskan penerapan nilai berjaya mempengaruhi sahsiah diri murid yang baik apabila murid-murid melaksanakan nilai-nilai positif dan meninggalkan nilai-nilai negatif.

Pengkaji luar negara turut menyokong hasil kajian ini seperti Thompson (2002) yang menjelaskan pengajaran sekolah termasuklah penerapan nilai-nilai dalam pembelajaran telah memberi pengaruh yang besar terhadap pembentukan dan perubahan sahsiah murid ke arah yang lebih baik. Hasil kajian beliau menjelaskan para pelajar menyatakan pengajaran guru merupakan pengaruh yang paling besar dalam pembentukan sahsiah diri mereka di samping faktor ibu bapa atau keluarga dan rakan sekolah. Selain itu, Purwokerto (2007) dalam kajiannya berkaitan dengan pendidikan nilai menjelaskan pendidikan nilai 
merupakan salah satu bahagian penting dalam pendidikan pada masa ini kerana peranannya sebagai salah satu elemen untuk mengembangkan watak optimisme dalam diri murid atau dalam erti kata yang lain nilai merupakan elemen dalam pembentukan sahsiah diri murid.

Seterusnya, Higgins (2007) serta Talts dan Kukk (2013) turut menyokong hasil kajian ini dengan menjelaskan penerapan nilai dalam pendidikan menumpukan kepada perkembangan kendiri dan moral murid yang mempengaruhi perkembangan kemahiran sosial murid dan seterusnya pembentukan sahsiah murid. Tripathi dan Tripathi (2015) juga berkongsi hasil dapatan yang sama iaitu pendidikan nilai mewujudkan persekitaran pengajaran yang kukuh yang seterusnya akan mempengaruhi sahsiah murid. Shoba dan Kala (2015) turut menjelaskan institusi pendidikan bukan sahaja berperanan untuk melengkapkan murid dengan ilmu pengetahuan tetapi juga memainkan peranan untuk membentuk sahsiah murid dengan penerapan nilai-nilai murni. Oleh itu, pengkaji menegaskan perkembangan murid perlulah sentiasa dipantau dan dibimbing oleh guru agar nilai-nilai murni menjadi sebahagian daripada sahsiah mereka.

\section{Cadangan untukKajian Lanjutan}

i. Bagi kajian akan datang adalah lebih baik sekiranya penerapan nilai dan pembentukan sahsiah murid Sekolah Kurang Murid luar bandar di Sabah berdasarkan dimensi kerana kajian ini hanya mengkaji kedua-dua aspek ini secara umum tanpa membahagikannya kepada dimensi-dimensi kecil.

ii. Selain itu, bagi kajian akan datang, diharap para pengkaji boleh melaksanakan kajian ini dalam ruang lingkup lokasi dan sampel yang lebih besar dan menyeluruh.

iii. Selanjutnya, bagi kajian akan datang, adalah lebih baik sekiranya kajian bukan sahaja dijalankan secara kuantitatif bahkan turut dijalankan secara kualitatif. Kesannya, dapatan kajian yang diperoleh akan lebih tekal

\section{Kesimpulan}

Kesimpulannya, walaupun kajian ini hanya melibatkan guru di daerah Ranau, Sabah sahaja, namun dapatan kajian ini telah memberikan sumbangan terhadap sistem pendidikan negara khusunya yang berkaitan dengan penerapan nilai dan pembentukan sahsiah murid di Sekolah Kurang Murid. Kajiankajian berkaitan dengan aspek-aspek ini perlu sentiasa ditambah agar tujuan utama sistem pendidikan negara yang ingin membentuk sahsiah murid yang seimbang dapat dicapai sekaligus memastikan aspirasi pendidikan negara dapat dikecapi.

\section{Rujukan}

Ab. Halim Tamuri, Khalthum Ibrahim, Nasruddin Yunos \& Azhar Ahmad. (2007). Orientasi amalan agama dalam kalangan remaja Melayu: Satu kajian di negeri Johor. Laporan Penyelidikan ATMA. Universiti Kebangsaan Malaysia.

Abd. Rahim Abd. Rashid. (2001). Nilai-Nilai Murni Dalam Pendidikan: Menghadapi Perubahan Dan Cabaran Alaf Baru. Kuala Lumpur: Utusan Publications \& Distributors Sdn. Bhd.

Abdul Rahim Hamdan dan Azharul Nizam Zahari. (2010). Konsep Pendidikan Bersepadu Serta Penerapan Nilai-Nilai Murni Dalam Pengajaran Matematik Menengah Rendah. Sains Humanika, $1-7$.

Abdul Rahim Hamdan, Azharul Nizam Zahari, Mohd Khairi Othman, Mohd Zailani Yusoff, Alis Puteh \& Nurfasihah. (2016). Perspektif Ibu Bapa Terhadap Permasalahan Dan Cabaran Dalam Pembentukan Nilai Murni Pelajar. Sains Humanika, 8(4-2), 9-16.

Ahmad Munawar, I., S. Zakaria \& S. Siti Aishah. (2012). "Islam dan Pembentukan Jati Diri Bangsa Melayu". Jurnal Hadhari, 143-154.

Amaludin Ab. Rahman \& Khadijah Alavi. (2007). Tren Gejala Sosial Di Kalangan Remaja: Kajian Kes Di Pusat Pemulihan Akhlak Malaysia. Malaysia Journal of Social Policy and Society, 4, 87-104. 
Asmawati Suhid, Abd Muhsin Ahmad, Syaza Mohd Sabri. (2015). Pendidikan Untuk Semua: Amalannya Dalam Sistem Pendidikan Islam Di Malaysia. International Journal of Education and Training (InJET), 1(2), 1-7.

Bartlett, J. E., Kotrlik, J. W., \& Higgins, C. C. (2001). Organizational Research: Determining Appropriate Sample Size in Survey Research. Informational Technology, Learning, and Performance Journal, 19(1), 43-50.

Connelly, L. M. (2008). Pilot studies. Medsurg Nursing, 17(6), 411-412.

Creswell, J. W. (2008). Educational Research: Qualitative, Quantitative, and Mixed Methods Approaches ( $2^{\text {nd }}$ ed.). Thousand Oaks: Sage Publication.

Ewington, J, Mulford, B, Kendall, D, Edmunds, B, Kendall, L \& Silins, H. (2008). Successful School Principalship In Small Schools. Journal of Educational Administration, 46(5).

Hair, J. F., Black, W. C., Babin, B. J., \& Anderson, R. E. (2010). Multivariate Data Analysis (7th ed.). New Jersey: Prentice Hall.

Hashim Bedu, Khairulhelmi Katip, Mohd Fahmi Mohd Sahid \& Syed Mohamed Syafeq Syed Mansor. (2008). Keruntuhan Akhlak Dan Gejala Sosial Dalam Keluarga:Isu Dan Cabaran. Johor Bahru: Fakulti Pendidikan Universiti Teknologi Malaysia.

Higgins, E. T. (2007). Handbook of social psychol- ogy (2nd ed). New York: Guilford

Jaclyn Ding \& Mohd Izham Mohd Hamzah. (2017). Tahap Kecekapan Pengurusan Disiplin Dalam Kalangan Guru-Guru Sekolah Rendah Daerah Baram. Prosiding Seminar Pendidikan Serantau Ke VIII. Fakulti Pendidikan: Universiti Kebangsaan Malaysia.

Khasnor Kamdi \& Sanitah Mohd Yusof. (2014). Penerapan Nilai Melalui Kurikulum Tersembunyi Dalam Kalangan Guru-Guru Sekolah Rendah di Daerah Johor Bahru. Konvensyen Antarabangsa Jiwa Pendidik, 11-13 August, 2014, Skudai, Johor.

Krejcie, Robert V. \& Morgan Daryle W. (1970). Determining Sample Sizes for Research Activities. Educational and Psychological Measurement, 607-610.

Maznah Ali \& Zakiah Zakaria. (2010). Persediaan Ibu Bapa dalam Pendidikan Rohani Terhadap AnakAnak: Kajian di Taman Batu Permai, Kuala Lumpur. Skudai: Fakulti Pendidikan, Universiti Teknologi Malaysia.

Mohamad Khairi Hj. Othman \& Asmawati Suhid. 2010. Peranan sekolah dan guru dalam pembangunan nilai pelajar menerusi penerapan nilai murni: Satu sorotan. South East Asia Journal of General Studies, 11, 117-130.

Mohd Arif Hj Ismail, Mohd Jasmy Abd. Rahman, \& Rosnaini Hj. Mahmud. (2005). Nilai-Nilai Murni Dan Pendidikan Bersepadu: Ke Arah Kemanusiaan Sejagat. Prosiding Wacana

Mohd Qhairil Anwar Azhar, and Zamri Mahamod. (2018). Tahap Perbezaan Pengetahuan, Sikap Dan Amalan Menggunakan Enam Topi Pemikiran Berdasarkan Jantina Dan Pengkhususan Dalam Kalangan Guru Bahasa Melayu Sekolah Kebangsaan. Jurnal Pendidikan Bahasa Melayu, 8(2).

Najuah. (2017). Strategi Pembelajaran Berbasis Pendidikan Nilai Dalam Pembelajaran Ips Di Sekolah. Prosiding Seminar Nasional Tahunan Fakultas Ilmu Sosial. Universitas Negeri Medan.

Nitce Isa Medina Machmudi Isa, Azlin Norhaini Mansor \& Jamalul Lail Abdul Wahab. (2017). Cabaran Kepimpinan Instruksional Guru Besar Di Sekolah Kurang Murid. Prosiding semiunar pendidikan serantau ke VIII. Anjuran Fakulti Pendidikan, Universiti Kebangsaan Malaysia \& Fakultas Keguruan \& Ilmu Pendidikan, Universitas Riau.

Nor Aishah Abdul Aziz \& Mohd. Zolkifli Abd. Hamid. (2014). "Inculcation of Values to Overcome Disciplinary Problems in Skill-based Educational Institutions". International Education Postgraduate Seminar (IEPS 2014). KSL Hotel, Johor Bahru.

Nor Suhara Haji Fadzil \& Jamil Ahmad. (2010). Kepentingan Kokurikulum Dalam Pendidikan Di Sekolah Menengah. Proceedings of the 4th International Conference on Teacher Education.

Norazri Mohd Zaidin. (2015). Penerapan Nilai-Nilai Murni Dalam Proses Pengajaran Dan Pembelajaran Ke Arah Pembentukan Sahsiah Pelajar Di Kolej Kemahiran Tinggi Mara. Tesisi Sarjana. Fakulti Pendidikan Teknik Dan Vokasional. Universiti Tun Hussien Onn Malaysia.

Purwokerto, S. (2007). Pendidikan Nilai: Telaah Tentang Model Pembelajaran. Jurnal Pemikir Alternatif Pendidikan, 12(1), 3-16.

Rohayati Derani. (2004). Persepsi Ibu Bapa Terhadap Faktor-Faktor Keruntuhan Akhlak Remaja Islam Masa Kini: Satu Tinjauan Di Taman Aman Anak Bukit, Alor Setar Kedah. Tesis. Universiti Teknologi Malaysia. 
Shoba S, Dan k, N. (2015). Value Education Towards Empowerment of Youth-A Holistic Approach. Procedia-Socilal And Behavioural Sciences, 172, 192-199.

Sjarkawi. (2008). Membentuk Kepribadian Anak Peran Moral Intelektual, Emosional dan Sosial Sebagai Wujud Integritas Membangun Jati Diri. Jakarta: Bumi Aksara.

Tajulashikin Jumahat, Fazura Mohd Noor, \& Mohd Burhan Ibrahim. (2013). Faktor-Faktor Penentu Stres Dalam Kalangan Guru: Sekolah Rendah Mubaligh Di Kuala Lumpur. Juku: Jurnal Kurikulum \& Pengajaran Asia Pacific, 1(2), 1-11.

Talts, L. \& Kukk, A. 2013. Learning and Teaching in The Context of The Value-Based Approach at The Younger School Level. Problems of Education in the 21 st Century, 142-152.

Thompson. W. G. (2002). The Effects of Character Education on Student Behavior. Dissertation. East Tennessee State University Digital Commons @ East Tennessee State University.

Tripathi, A dan Tripathi, B. C. (2015). Value Based Education and Human Development. International Journal of Scientific and Innovative Research, 3(1), 152-154. 